\title{
SELF-REGULATION TRAINING AND PREVENTION OF NEGATIVE HUMAN FUNCTIONAL STATES AT WORK: TRADITIONS AND RECENT ISSUES IN RUSSIAN APPLIED RESEARCH
}

\author{
Anna B. Leonova, \\ Alla S. Kuznetsova, \\ Valentina V. Barabanshchikova \\ Lomonosov Moscow State University \\ Moscow
}

\begin{abstract}
The paper is devoted to consideration of self-regulation training that can be used in order to prevent a development of negative human functional states (HFS) in work environment. According to the well-developed in Russian work and organizational psychology traditions the effects of practical implementation of various self-regulation methods on job efficiency and worker's well-being are analyzed. The positive patterns of changes in HFS syndromes taken place as a result of prolonged courses of self-regulation training are described. It is shown that a successful acquisition of self-regulation skills strongly depends on (1) specificity of job content and (2) individual sensitivity to various relaxation techniques. These findings are useful for enhancing the quality of work-site stress management and health promotion programs.
\end{abstract}

Keywords: occupational stress, human functional state, self-regulation, stress management, relaxation effects, individual differences, health promotion programs.

Over the past decades one of the most important lines of research in Russian applied psychology concerns the elaboration and practical implementation of psycho-prophylactic programs and tools for enhancing personnel workability and preventing a development of negative human functional states (HFS) at different job conditions (Leonova, 1994; 2007; De Keyser \& Leonova, 2001). Initially these research were focused on correction and prevention of such negative HFS as acute fatigue, monotony / boredom, emotional overstrain, etc., which considered as the serious risk-factors for reliable work of operators in highly automated systems at military objects, aviation, rail-way traffic, complex industrial 
technologies, etc. Even at that time the accent was done not only on implementation of sufficient ergonomic redesign of the operator's work places but also on the use of self-regulation techniques that could help a person to be more resistant to intensive workloads and job demands (Dikaya, 2003; Leonova \& Kuznetsova, 1993; Lobzin \& Reshetnikov, 1986). Recently this approach has been successfully developed and become a "core part" of stress-management (or, more correctly, HFS management) programs that are widely used in the psychological assistance services at civil enterprises. Among the occupational groups most frequently participated in such training programs there could be mentioned medical doctors, teachers, sellers, call-centers' operators, office workers and athletes (Leonova, 2007; Leonova \& Kuznetsova, 2007). At the same time, a prospective development of this type of practice ought to be grounded on the relevant conceptual basis and scientifically verified data of empirical studies. The present paper is devoted to the methodology of HFS management research illustrated by the new findings in the effects of self-regulation training on workers' well-being and job efficiency.

\section{Basic principles of HFS management and self-regulation training}

Human functional state (HFS) is one of the central concepts in Russian applied psychology initially developed in the field of work and engineering psychology and, recently, in organizational psychology (Leonova, 2003; Zinchenko \& Munipov, 2001). Generally speaking, this concept concentrates on revealing the relations between the achieved level of work efficiency and individual resources of a worker that were utilized by him in order to perform job tasks. According to the activity regulation approach developed in Russian psychology, HFS is defined as a relatively stable integrative pattern of activated internal resources (physiological, cognitive and emotional) that highlights the mechanisms of activity regulation in the current situation and determines the efficiency of work performance in actual job conditions (Leonova, 1994; 2003). The theoretical framework of HFS research is based on the data of job analysis in order to distinguish the sets of objective work factors that lead to changes in HFS. By means of this methodology, any type of HFS could be represented as a structural pattern of actualized physiological 
and mental functions which are involved in the process of work execution (Hockey, Gaillard \& Burov, 2003; Leonova, 1996).

In applied studies the main tasks of HFS management are usually considered as follows: (a) enhancement of work efficiency, (b) reduction of errors and false actions probability, (c) normalization of an actual workers' mental and physical state, (d) prevention of negative chronic states accumulation (like chronic fatigue, emotional exhaustion, depression, etc.), (e) prophylactics of work-related somatic diseases. The individual's capacity to maintain an adequate level of resources involved in work process helps to be effective in work. Thus, one of the promising ways to organize an efficient psychological support in job conditions is to elaborate and implement special programs targeted to optimize HFS at work and to teach people how to manage their states during the process of work execution.

Developed in Russian work and health psychology HFS management tools are to some extent similar to a Western framework for stress-management studies, since stress can be considered as one of the negative individual states. There are several categories of optimization methods and techniques which can be drastically differentiated by their "goal-orientation." In one case their aim consists in elimination (or reduction) of influence of objectively demanding job conditions and intensive workloads (i.e., ergonomic redesign of workplaces and technical devices, normalization of work / rest schedules, etc.). Another category of methods relates to different ways of external stimulation or reassurance of a person - by using light psychopharmacological means, location in a more comfortable environment (functional music, multimedia compositions) or suggestion; in all these cases subjects have a passive position. The third category of methods is based on active learning of new habits and skills that can help subjects to overcome the difficulties by themselves - for instance, by training professional and communicative competencies, resolving conflict situations and applying other useful coping strategies. Different procedures of self-regulation training belong to the third category (Everly \& Rosenfeld, 1981; Leonova \& Kuznetsova, 2007).

Among the mentioned categories of HFS management methods selfregulation techniques build up the most promising group with respect: 1) to the subject's active conscious participation in managing his / her own states, 2) to development of the so-called internal psychological HFS regulation skills, 3) to high usability of actualization of these skills when 
necessary - a person can use them at any time and in any place when and where it becomes necessary. All self-regulation techniques are oriented to learning special regulatory skills which after consolidation form the new and stable psychological habits of managing his / her own states. In work conditions these habits allow to transform an experienced non-optimal HFS to appropriate or optimal levels (Dikaya \& Semikin, 1991; Leonova, 1993; Leonova \& Kuznetsova, 1993). These techniques include various tools of relaxation and subsequent mobilization of internal resources, which should be reached according to the near future work / activity tasks. Among them there are well-known techniques that are useful for purposes of psychological HFS self-regulation, such as progressive relaxation (Jacobson, 1938), autogenic training (Schultz, 1983) and some intermediate methods based on the main similar principles, namely ideomotor training and visualization (Leonova \& Kuznetsova, 2007).

It is obvious, that psychological self-regulation skills are widely present in the psychological structure of any human being's activity, otherwise one would not be able to maintain one's existence in the world. A new direction in self-regulation training with respect to HFS management in work is elaboration of special skills which could be developed during special self-regulation training courses and then used by the subject himself to manage his / her HFS in the most optimal way. Understanding of the optimal way implies such characteristics as high probability of reaching the required HFS level with respect to different work tasks, the limited time for the usage of HFS management procedures, full conscious understanding by a subject of the necessity and the targets of HFS management, and full conscious control of the ways of HFS regulation.

The Russian history of HFS self-regulation techniqies' employment in work domain started from aviation and aerospace, where HFS selfregulation means were originally implemented at the beginning of the 1960s. Self-regulation training, including mostly programs based on autogenic training and progressive (neuro-muscular) relaxation, was used as part of pilots' professional training and also as part of different rehabilitation programs (Grimak \& Khachaturiants, 1981; Marischuk, Platonov, \& Pletnitski, 1969). The reasons for introduction of self-regulation training in this field were both work specificity-related and financial ones. In aviation and aerospace people usually do their work under extreme conditions and emergency situations. Nevertheless it is of great 
importance to maintain high work reliability and efficiency, because the "price" of work errors here is too high. That is why government financial support was traditionally stronger here.

Some times after self-regulation methods were extended to certain types of operator's occupations, where a broad range of stress and fatigue reduction means are traditionally used. Then the practical implementation of self-regulation spread to the other fields where ordinary work conditions are classified as extreme: mining and fishing industries. In the early 1970s self-regulation training programs extended not only to the occupations with extreme work conditions but to other industries: metal-working, manufacturing industry, microelectronics, etc. From that time on, self-regulation methods as HFS management tools became quite common in many industrial companies.

Rapid practical implementation of self-regulation training courses could be explained by its double effect. First, it raises the level of HFS after each training session, so it is possible to eliminate the negative consequences of work tension. Second, self-regulation training helps a person to develop new internal habits that could be used where and when this seems to be necessary without any additional help from another person, either a psychologist or somebody else. So, after a complete course of self-regulation training a worker develops a relatively well-established habit of helping himself to cope with poor well-being, control emotional reactions in work, and prevent work fatigue.

Self-regulation training in Russian enterprises was put into practice in work settings in different organizational forms, so in all cases it was necessary to conduct training courses consisting of several sessions. Self-regulation techniques were implemented in two ways: at the stage of occupational training (for instance, in aviation), and directly in work conditions. Organizational aspects of work in many enterprises made it possible to conduct self-regulation training courses not only before or after work shifts, but also in the course of work shifts during special breaks in work process. This proved to be reasonable because of the mentioned above specific feature of self-regulation training: the positive effects on HFS could be reached during each individual training session, so even primary training helps to reach the required HFS level.

From the middle of the 1970s HFS recovery procedures in work settings were applied as a special organizational form - the so-called "relaxation premises" (RP). Relaxation premises are the places used for rest 
and self-regulation training during work shifts under the professional guidance of qualified psychologists, and specially equipped for the purpose of supporting the relaxation and self-regulation. In the mid-1980s the development of relaxation premises concentrated more and more on the idea that self-regulation training is an effective way to improve individual resistance to stress, raise reliability, maintain a high level of work efficiency, and increase work satisfaction. Consequently, it was considered useful in protecting physical health and preventing mental disorders.

The accumulated unique experience in the development of RP helped to transform relaxation premises into relaxation centers by the end of the 1980s - centers which included a variety of premises to suit different purposes. There used to be two main purposes: (1) rest and relaxation during work breaks supported by listening to music programs and / or watching relaxation slides and video films, and (2) the development of habits of HFS management using self-regulation training (Leonova \& Kuznetsova, 2007).

Relaxation premises had different interior design concepts determined by their functional specificity. When the premises were used as resting places, the design was elaborated in order to stress the contrast between working space and resting space. This contrast is constituted by sound isolation, in color schemes, in the range of accessories. For instance, it was quite popular to build fountains with colored lighting, to hang pictures and install colored dynamic panels on walls and ceilings, to put in plenty of plants and flowers, etc. In those cases when the $\mathrm{RP}$ were used as places to practice self-regulation habits, the design concept was different, because it was subordinated to the task of the subjects' maximum concentration on their own state without any distraction of attention from this goal. That is why colorful and unusual details on the relaxation premises could interfere with the training process, so the design was more restrained; there were not many striking accessories.

The long history of self-regulation training in work environment in Russia could be recognized as positive and promising results. A variety of different self-regulation training methods were practiced in work settings: autogenic training, progressive relaxation, imagination training and various programs based on different combinations of these methods (Leonova \& Kuznetsova, 2007). According to almost all publications, a 
positive effect of self-regulation training on the dynamics of HFS and work efficiency was reached. Self-regulation effects prove the gradual process of transformations of self-regulation exercises into the special internal skills, or the self-regulation habit. New skills used during work hours help to improve work performance when necessary. The systematic use of self-regulation skills helps to protect human physical and mental health.

\section{Systemic analysis of HFS dynamics during the process of self-regulation training}

The main results of implementation of activity regulation approach to HFS in practice show that any type of HFS manifests itself on different levels: (a) energetic or physiological level of activity regulation, (b) operational level of cognitive functioning, (c) reflective (or self-evaluative) level, and (d) resulting level of work performance and behavior (Leonova, 1994; De Keyser \& Leonova, 2001; Hockey et al., 2003). It means that HFS investigations need multidimensional assessment, and sets of different HFS indicators should be processed in order to show not only shifts in various HFS manifestations, but also changes in functional structure of work activity (Leonova, 1996; 2003; 2007).

As an example of achieved structural changes in HFS dynamics during self-regulation training the following study could be shown. The study was a part of the comparative research program on the effects of self-regulation training and was conducted with the students of the Faculty of psychology, Lomonosov Moscow State University (Leonova, 2007). All participants of the study (28 female and male persons at the age of 20-42) passed through the whole circle of the self-regulation training program that includes 8-10 consequent sessions. In parallel with the training sessions several diagnostic "cuts" of HFS manifestations were made - in the beginning, in the middle and at the end of the course of self-regulation program.

The complex of standardized diagnostic tests was used for HFS assessment. The measures were subdivided into two groups: (1) cognitive tests for working memory and attention span, (2) subjective scales for HFS self-estimation: well-being scale; Russian modified versions of Spielberger's state-anxiety, state-anger and state-depression scales; Izard's differential emotions scale. Besides, two additional assessment sets were 
Self-Regulation Training and Prevention of Negative Human Functional States at Work 489

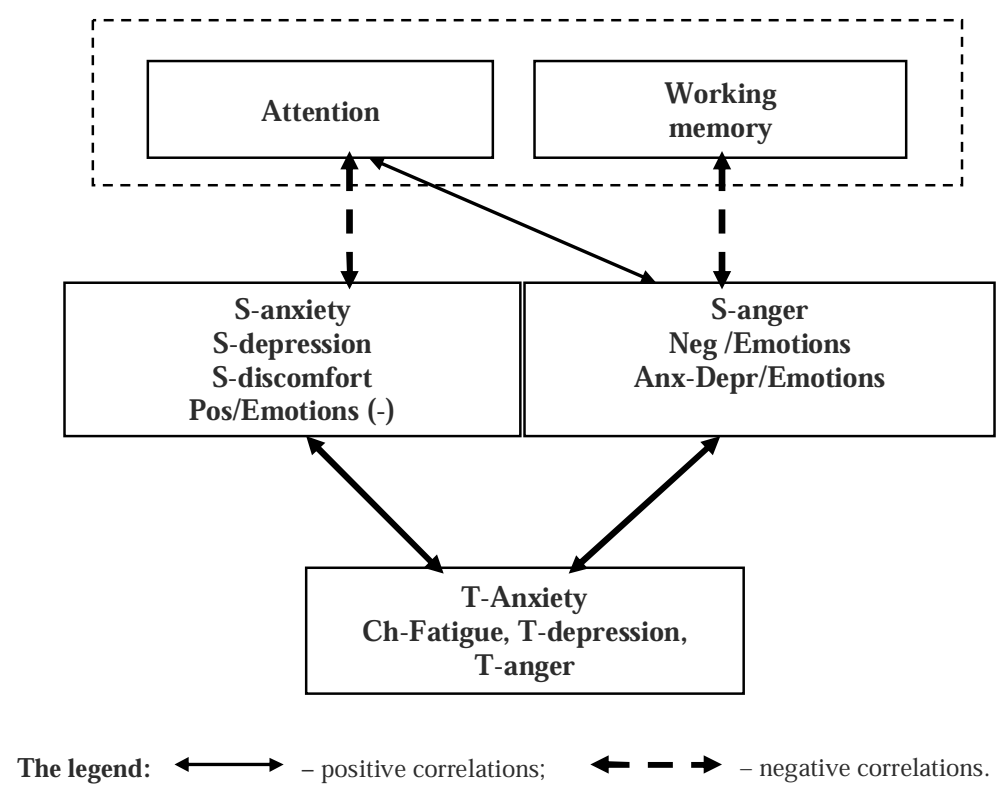

Figure 1. The structure of HFS syndrome before the beginning of the self-regulation training course: syncretic, non-structuring reflection of subjective moods

conducted before the beginning and after the end of the training course to test individually stable characteristics - (1) chronic fatigue and (2) trait anxiety, anger and depression according to Spielberger's scales.

The comparison of actual state and trait dynamics as a result of the self-regulation course helps to highlight distinctly the typical changes in HFS syndrome from the beginning till the end of the training program. The obtained results showed the statistically significant improvement of all current HFS indicators (one-way ANOVA). Indices of operative memory and attention capacity increased $(p<0.01)$. Different aspects of HFS self-esteem reflect positive changes: well-being increased $(p<0.01)$ as well as the distinct manifestations of positive emotions of interest, happiness and surprise $(p<0.01)$. Indices of state anxiety and associated depressive emotions like fear, shame and fault decreased significantly $(p<0.05)$. In general the positive emotional "colors" of the current HFS 
acquired more intensive bright accents. There were also positive changes in some individual characteristics. The level of chronic fatigue reduced to minimal grade $(p<0.05)$. Also a tendency of decreasing the level of trait anxiety was found $(p<0.1)$. These data demonstrate the efficiency of even a quite short self-regulation training course with respect to mental health and personal well-being improvement.

In the clearest way the positive influences of self-regulation training are represented by the differences in the correlation patterns with the whole set of diagnostic indicators being collected (1) in the beginning and (2) after the end of the training (see Figures 1 and 2). At the beginning of the training course almost all HFS self-esteem indicators are smoothly intercorreleted. That is an evidence of a very poor differentiated and highly tight combination of emotional feelings before the training course (see Figure 1). Almost all negative emotions are in inverse ratio to cognitive processing indicators. The only exception is the positive correlation between state-anger and attention span indicators

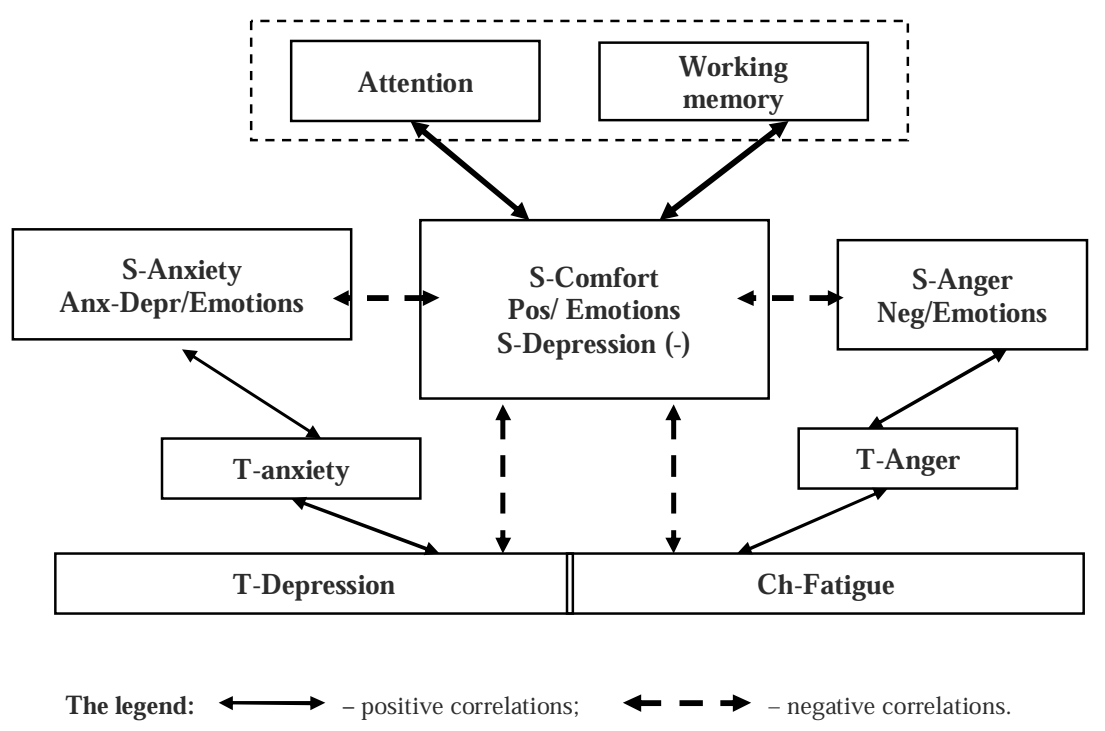

Figure 2. The structure of HFS syndrome after the end of the self-regulation training course: "emotional granularity" 
that could be interpreted as the dominating of "threat-searching" and "negative fixation" of non-optimal coping strategies.

After the end of the training course the type of correlation pattern is more diversified and highly structured (see Figure 2). HFS self-estimations become to be subdivided into several unique groups: positive emotions, anxiety manifestations and acute negative emotions. Correlation links of these actual state indicators with more stable personality traits could be described as a more streamlined combination. Positive emotions have the highest amount of significant correlations and are linked directly with the cognitive indicators.

The data obtained concerning the differences in correlation patterns help to indicate a more differentiated structure of HFS syndromes after accomplishment of the self-regulation training course. This effect shows an increased ability of a subject for a more precise and meaningful reflection of his / her emotions and feelings in relation to cognitive functions. It is quite appropriate to use here the term "emotional granularity," frequently used in the studies of emotional intelligence. This term helps to understand the nature of individuals' abilities to reflect the differences between various emotional feeling and then to use this experience for a more adequate choice of coping strategies. It allows us to make the following conclusion: a systematic course of self-regulation training helps to develop a more structured and sensible image of subjectively experienced HFS. Such changes in reflective processes lead to enrichment of individual's self-management skills.

\section{How to achieve the best training effects: different ways to enhance efficiency of self-regulation}

Despite the proved usability of self-regulation techniques, the "problem of choice" of the most adequate self-regulation techniques and methods which should be chosen for implementation in the specific work domain is of vital importance. Looking for a proper answer to this question it is necessary to take into consideration two aspects of the problem: (1) an influence of occupational and work specificity on acquisition of self-regulation skills, and (2) an impact of individual differences among people from the point of view of their psychological sensitivity to various self-regulation methods. 


\subsection{Efficiency of self-regulation training in different occupational groups}

An elaboration of the first aspect of the "problem of choice" is related with a necessity to understand to what extent the specificity of professional demands and job contents could influence efficiency of self-regulation training. From practical point of view this knowledge is important for arranging more sufficient self-regulation programs for different occupational groups.

Over the past decades at the Laboratory of Work Psychology, Lomonosov Moscow State University there was conducted a wide range of empirical studies in order to elaborate the main principles of organization of self-regulation training courses and their direct implementation in work environment. The main purpose of these studies consisted in an integrative evaluation of the effects of different self-regulation techniques on dynamics of workers' HFS manifestation in various occupational groups. It means that the sets of indices of the most important physiological and psychological functions were measured before, during and after the implementation of self-regulation courses. Then a comparative analysis of the collected data sets was produced. The results help to differentiate the dominant positive effects on HFS management programs depending on the specificity of job content and preferable types of self-regulation techniques in different occupational groups.

In general, the samples of nine occupational groups participated in the studies: (1) blue-collar workers of microelectronic plants, (2) industrial managers, (3) operators of high automated systems, (4) air-traffic controllers, (5) operators of booking offices, (6) accounting workers, (7) medical doctors, (8) school teachers and (9) students (Leonova, 1996; Leonova, \& Kuznetsova, 2007). In all groups the dynamics of individual's HFS was evaluated by a complex of diagnostic indicators for measuring the changes in physiological, cognitive and subjective levels of activity regulation. In each group, this complex was assembled according to the context of the main professional tasks which was revealed by the results of job analysis. A combination of the used diagnostic measures was accomplished on the basis of the HFS research methodology according to two main postulates: a) the indicators should be adequate to the job content in concrete occupations, and b) experimental results obtained 
for different occupational groups should be comparable. The prepared diagnostic complex included:

- several common physiological indices and indicators (blood pressure; heart rate; vegetative index Kerdo);

- psychophysiological and cognitive performance tests (critical frequency of the flicker test (CFF); modified Burdon checking test ${ }^{1}$ );

- subjective tests of self-estimation of HFS (well-being scale; Spielberger's state-anxiety scale; acute fatigue scale) (Leonova, 1994; 1996; De Keyser \& Leonova, 2001).

During each study three self-regulation techniques were used: (a) progressive neuro-muscular relaxation training; (b) sensory-motor imagination and image reproduction; (c) modified version of autogenic training. All these techniques were arranged in the form of sequential stages of acquisition of self-regulation habits and, in the whole, correspond to the basic elements in the unified complex system of self-regulation training (Leonova \& Kuznetsova, 1993; 2007). Several additional rehabilitation procedures were used at each stage of the program (different types of breathing and muscular gymnastics, music and multimedia accompaniment). They were used in order to increase the relaxing and / or activating influences of self-regulation techniques. The general description of the proposed complex system is presented in Table 1 . The number and content of single sessions at each stages of training could be varied (from 2 till 4) that depended on a "readiness to learn" of the subjects in different occupational groups, but the sequence of the main stages was always the same.

The effects of self-regulation techniques were compared with the results of diagnostics measures which were conducted during the whole training course. First, the specific effects of using self-regulation techniques in each of the occupational groups were identified, and then the main tendencies in dynamics of the background HFS level were evaluated with the respect to a prolonged usage of self-regulation techniques. Second, a comparison of efficiency of self-regulation training in different

1 The modified version of the Burdon test was used as a correlate measure for the assessment of probability of errors. For this purpose it was executed in the form of a special loading model. 
Table 1

The complex program of self-regulation training

\begin{tabular}{|c|l|l|l|c|}
\hline Stage & $\begin{array}{l}\text { Self-regulation } \\
\text { technique }\end{array}$ & \multicolumn{1}{|c|}{ Content of stages } & \multicolumn{1}{|c|}{$\begin{array}{c}\text { Additional } \\
\text { procedures }\end{array}$} & $\begin{array}{c}\text { Duration of a } \\
\text { single session }\end{array}$ \\
\hline 1. & $\begin{array}{l}\text { Progressive } \\
\text { (neuro-muscu- } \\
\text { lar) relaxation }\end{array}$ & $\begin{array}{l}\text { Development of sub- } \\
\text { jective feelings of a } \\
\text { relaxation state, deep } \\
\text { muscular relaxation }\end{array}$ & $\begin{array}{l}\text { Verbal instructions; } \\
\text { breathing exercises; } \\
\text { general and pos- } \\
\text { tural gymnastics }\end{array}$ & $20 \mathrm{~min}$. \\
\hline 2. & $\begin{array}{l}\text { Sensory-motor } \\
\text { imagination } \\
\text { training }\end{array}$ & $\begin{array}{l}\text { Transition to the } \\
\text { voluntary relaxation } \\
\text { of main muscular } \\
\text { groups and body in } \\
\text { the whole }\end{array}$ & $\begin{array}{l}\text { The same plus mu- } \\
\text { sic and multimedia } \\
\text { compositions }\end{array}$ & 20 min. \\
\hline 3. & $\begin{array}{l}\text { Autogenic Train- } \\
\text { ing }\end{array}$ & $\begin{array}{l}\text { Self-ordering by } \\
\text { verbal formulas and } \\
\text { auto-suggestion }\end{array}$ & $\begin{array}{l}\text { All mentioned } \\
\text { above }\end{array}$ & 15 min. \\
\hline
\end{tabular}

occupational groups was done. The influence of self-regulation training was evaluated in two forms:

a) Actual effects of self-regulation sessions. These effects can be evaluated by comparison of the data before and after each selfregulation session during the training course.

b) Prolonged effects throughout the whole course of training. These effects can be revealed by a comparison of background data gathered before the training sessions at different stages of realization of the self-regulation program.

An overview of the collected data allows us to make the following predictions: (1) application of different self-regulation techniques leads to HFS optimization both in the respect of actual effects (immediately after each training session) and prolonged effects (stable positive cumulative changes); (2) the efficiency of different self-regulation techniques may have varied impacts on HFS dynamics in different occupational groups because of the specificity of job content and demanding work conditions; (3) self-regulation methods based on the active application of mental skills in the HFS management (sensory-motor imagination training and autogenic training) have more positive effects on those negative workers' states which are strongly provoked by psychological factors. 


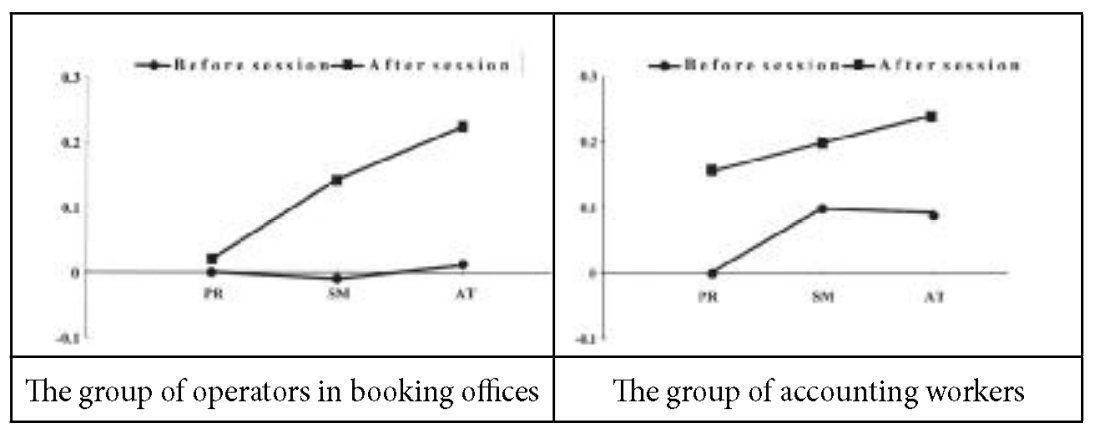

The legend: PR - progressive relaxation;

SM - sensory-motor imagination training;

$\mathrm{AT}$ - autogenic training.

Figure 3. The general actual and prolonged effects of self-regulation training (the data are presented in total integrative relative scores calculated for the whole sets of indicators)

The results obtained show that the pronounced positive effects can be achieved while using every self-regulation techniques in all occupational groups. As an example, at the figure 3 there are presented the data of HFS dynamics during self-regulation course in the two occupational groups (A) operators in booking offices, and (B) accounting workers. For this purpose the integrative scores of HFS indicators ${ }^{2}$ were calculated on the basis of standardization of particular scores of the following indicators: accuracy and productivity of the checking test; CFF parameters; general indices of well-being, state-anxiety, and acute fatigue scales. The initial scores were checked before the beginning of training course - they were considered as a starting position and evaluated as so-called initial "zero level." The dynamics of integrative HFS score between other stages of the training course could be interpreted in terms of their deflections to a better or worse level from this starting position. The presented data suggest that there is obvious increasing of integrative HFS scores during the process of self-regulation training. They manifest many positive changes under the influence of these procedures. The prolonged effects of self-regulation training are expressed strongly in the case of the group of accounting workers.

2 For more details see (Leonova, 1994; 2003). 
It has to be mentioned that the positive actual effects of the self-regulation sessions are clearly pronounced in all groups of particular HFS indicators. The type of achieved improvement of integrative HFS scores after each self-regulation sessions can be qualified as a general activity mobilization. This reflects a well-balanced enhancement of parameters of physiological and cognitive functioning as well as increase of subjective and emotional feelings (for comparison, see Naenko, 1976; Leonova, 2007). At the same time there are some specific effects which depend upon the differences between occupational groups. The changes in HFS indicators show that in each group there are several mental and psychophysiological indices which are more sensitive to the influence of self-regulation training. They correspond with the most important professional functions that are directly involved in the process of job execution.
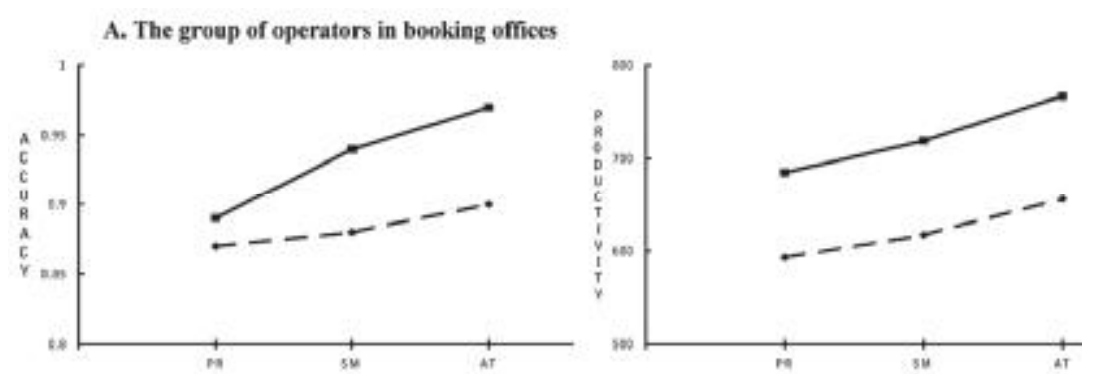

B. The group of accounting workers

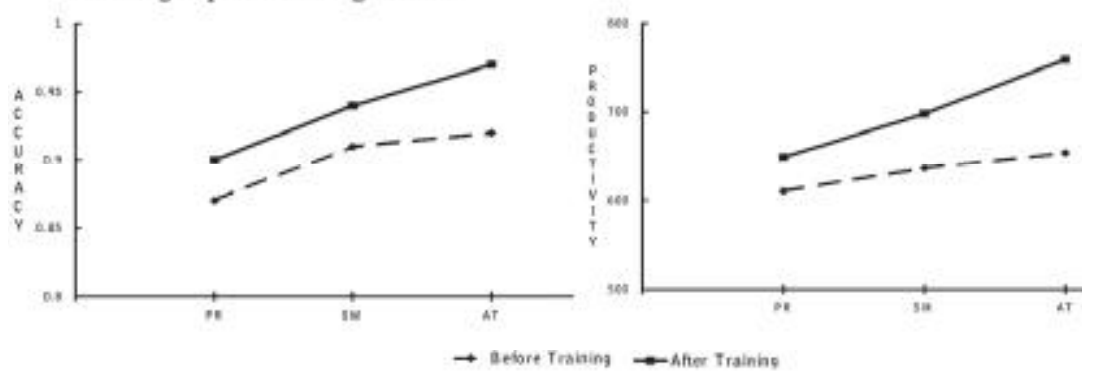

The legend: $\mathrm{PR}$ - progressive relaxation;

SM - sensory-motor imagination training;

$\mathrm{AT}-$ autogenic training.

Figure 4. Effects of self-regulation training on the indicators of cognitive performance 
A specificity of the positive effects was also observed in the indicators of cognitive performance (see Figure 4). After applying different self-regulation procedures both indicators of the Burdon checking test (accuracy and productivity) are growing. That means that the speed of the task execution increases, and the number of errors declines. This result could be interpreted in terms of minimization of the so-called "attention errors," which usually occur when a worker's state changes from an "optimal level" to fatigue.

Concerning the prolonged effects of self-regulation training, the following results were obtained (see Table 2 and Figure 3). When subjects were trained systematically, the positive results were reached with respect to all HFS indicators. The registered physiological indicators (blood pressure and heart rate) demonstrate a trend towards a general normalization: from mostly negative background values (either too high or too low) to the level of an optimal range. In general, the psychophysi-

Table 2

The prolonged effects of self-regulation training in different professional groups

\begin{tabular}{|c|c|c|c|c|c|c|c|c|}
\hline Occupational groups & 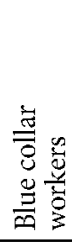 & 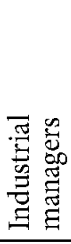 & 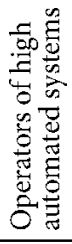 & 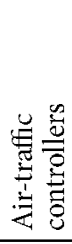 & 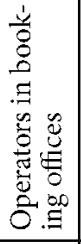 & 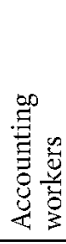 & 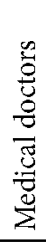 & $\begin{array}{l}\frac{0}{0} \\
\frac{D}{0} \\
\frac{D}{8} \\
\frac{8}{0} \\
\end{array}$ \\
\hline Blood pressure & $+!$ & + & + & 0 & 0 & $+?$ & + & $+?$ \\
\hline Well-being score & + & 0 & + ? & $+!$ & 0 & $+!$ & + & + \\
\hline State anxiety score & + & 0 & + & 0 & + & 0 & + & + \\
\hline Acute fatigue score & +1 & & + & & 0 & $+!$ & $+?$ & $+?$ \\
\hline Critical Fusion frequency & & & & & $+?$ & 0 & & \\
\hline Accuracy in Checking Test & & & & $+!$ & 0 & $+!$ & & \\
\hline Productivity in Checking Test & & & & $+!$ & + & + & & \\
\hline Trait anxiety score & $+?$ & $+?$ & $+?$ & & & & + & + \\
\hline Chronic fatigue score & + & $+?$ & + & & & & $+?$ & + \\
\hline
\end{tabular}

The legend: Positive effects: + ! $(p<0.01) ;+(\mathrm{p}<0.05) ;+$ ? $(\mathrm{p}<0.1)$. No effects: 0 . The measure was not used: free space. 
ological and cognitive performance indicators, as well as the indicators of HFS self-estimations and emotional feelings, are transformed in a positive way.

The mentioned positive prolonged effects were shown in all occupational groups, but their grades were different. For instance, in the group of accounting workers the positive changes in the background HFS scores started to be highly explicit even at the middle of self-regulation course (see Figure 3). At the same time, in the group of operators in booking offices these changes were not so obvious. Such ambiguous (but only for the first sight) result reflects the extremely increased daily workloads in this occupational group during the whole period of implementation of self-regulation program. Nevertheless, to the end of the training course the background HFS level started to be increased positively. This trend could be interpreted as an improvement in such components of the operators' HFS which suffered more under the influence of intensive workloads in the ordinary course of job execution.

Such deficiency of the HFS components is not the same in different occupations (see Table 3). The data obtained show that in the group of industrial managers the most explicit positive changes manifest themselves in normalization of physiological support of activity; in the group of air-traffic controllers - in the improvement of cognitive performance and increasing feelings of subjective comfort; in the group of operators in booking offices - in the decreasing of emotional tension and the increasing speed of information processing; in the group of accounting workers - in the decrease of acute fatigue symptoms and the increasing quality of visual information search.

Table 3

Prolonged positive effects in different occupational groups (based on Wilcoxon signed ranks test, $p<0.05$ )

\begin{tabular}{|c|c|c|c|c|}
\hline $\begin{array}{l}\text { Occupati- } \\
\text { onal groups }\end{array}$ & $\begin{array}{l}\text { Industrial } \\
\text { managers }\end{array}$ & $\begin{array}{l}\text { Air-traffic } \\
\text { controllers }\end{array}$ & $\begin{array}{l}\text { Booking offices } \\
\text { staff }\end{array}$ & $\begin{array}{l}\text { Accounting } \\
\text { workers }\end{array}$ \\
\hline $\begin{array}{l}\text { Type of ef- } \\
\text { fects }\end{array}$ & $\begin{array}{l}\text { normalization } \\
\text { of physiologi- } \\
\text { cal support of } \\
\text { activity }\end{array}$ & $\begin{array}{l}\text { - improving } \\
\text { of cognitive } \\
\text { support of } \\
\text { activity; } \\
\text { - increasing } \\
\text { subjective } \\
\text { comfort }\end{array}$ & $\begin{array}{l}\text { decreasing } \\
\text { emotional ten- } \\
\text { sion; } \\
\text { increasing } \\
\text { the speed of } \\
\text { perception }\end{array}$ & $\begin{array}{l}\text { - decreasing of } \\
\text { acute fatigue; } \\
\text { - increasing } \\
\text { of quality of } \\
\text { perceptual } \\
\text { processing }\end{array}$ \\
\hline
\end{tabular}


The comparison of both actual and prolonged effects of self-regulation training demonstrated a cumulative character of the positive trends. While after the first sessions mostly in all occupational groups the HFS indicators showed a slight tendency towards positive changes, at the end of the training course this dynamics became vividly manifested and stable (see for the most evident example the results of operators in booking offices, Figure 3 ). These results demonstrate the gradual transformation of overt execution of self-regulation exercises into the special mental skills or a development of self-regulation habits.

The described above data could be summarized as follows. The positive effects of self-regulation training on workers' well-being and mental functioning are distinctly manifested in all observed occupational groups. This improvement can be achieved by the use of all self-regulation techniques which were included in the proposed training program. A possibility of developing self-regulation habits makes a good basis for the prevention of human errors, losses of personnel workability and mental / physical health deterioration. At the same time, the obtained results show that the efficiency of the distinct self-regulation techniques is not equal. For instance, in the group of industrial managers the most positive dynamics was observed after using the progressive relaxation technique. In the air-traffic controllers' group the most explicit results were achieved after the sessions with sensory-motor imagination and autogenic training. In the group of operators in booking offices and in the group of accounting workers the most pronounce positive dynamics took place at the end of the whole self-regulation course, e.g. after the session with autogenic training.

In addition, several general tendencies in manifestations of the efficiency of different self-regulation techniques have to be mentioned. First of all, the most distinct positive effect is always observed for some, but not for all HFS indicators, while the trends towards a HFS optimization in the whole are the same for all self-regulation techniques. Secondly, the most "psychologically-oriented" techniques - such as sensory-motor imagination and autogenic training - have a stronger effect on the emotional and cognitive components of activity regulations, while the progressive relaxation procedure makes it possible to normalize mostly the level of psychophysiological tension and to minimize negative exhaustion and psychosomatic complaints. 


\subsection{Individualized adaptation}

\section{of self-regulation training courses}

Besides the occupational specificity, it is necessary to take into consideration individual differences between people who participate in self-regulation training courses. The fit between the content of job and the choice of the most appropriate self-regulation techniques is the first important principle for a better design of self-regulation programs. The second one consists in taking into account the individual abilities and preferences of participants in such psychological interventions.

It seems that an individualized approach to using self-regulation techniques promotes better results of their practical application. Such approach could be considered as a potentially fruitful way for increasing human reliability and maintaining HFS at an optimal level in different work settings. Despite common opinion that any kind of self-regulation techniques is rather efficient for developing internal self-regulation skills, it could be more sufficient to define the basic lines of individualized adaptation. A realization of this intention has to be grounded on the answer to the following initial question: "Are there any reasons to say about the individual / personal abilities or characteristics that have an influence on acquisition of self-regulation skills?"

There are not so many research devoted to investigation of individual psychological factors that mediate the self-regulation training effects. Among various individual characteristics the dominant sensory modality of human imagery is promising (Barabanshchikova \& Kuznetsova, 2003; Kuznetsova \& Barabanshchikova, 2005). The point is that all self-regulation and relaxation techniques are different with respect to the type of basic exercises, and these exercises are related to activation of different areas of human imagery modalities. Progressive relaxation exercises address their influence mostly to kinesthetic modality of imagery - by forming sensations of warmth and heaviness in a body. Sensory reproduction exercises are targeted to reconstruction of visual image of a relaxing situation by means of visual modality involvement (Benson, 1999; De Keyser \& Leonova, 2001; Everly \& Rosenfeld, 1981; Jacobson, 1978; Mitchell, 1977; Luthe, 1969).

In any case HFS management procedures based on self-regulation techniques are directed to the construction of an "image of relaxation state," and this image can be built up in various ways - for example, with 
the help of visual or kinaesthetic imagery. So, it is possible to pin down at least one basic individual characteristic potentially relevant to selfregulation training - namely, the dominant sensory modality of human imagery. Of course, it is very important to emphasize that polymodality of images is proved, and various sensory modalities should be integrated in the complete image (Hilgard, 1977). At the same time, it is reasonable to assume that one of these modalities could be dominant and plays an instrumental role in image constructing.

In order to check the modality congruency / dissimilarity effects on HFS dynamics through application of self-regulation procedures a special study was conducted on the samples of (a) university students (131 subjects including 8 males, aged from 19 to 28), and (b) athletes of high qualification (16 males, aged between 21 and 28). Nine athletes represented the judo team, the rest - the boxing team. These kinds of sport were chosen because of peculiarities contented in judo and boxing athletes' activity structure. In judo wrestling athletes pay most attention to kinesthetic feelings as the special type of partner's feedback. On the contrary, boxers take into consideration mainly visual signals that control these athletes' activity.

At the first stage of the study questionnaire-based assessment of the dominant sensory modality (Marks, 1999; Lequerica, Rapport, Axelrod, Telmet, \& Whitman, 2002) and various imagery-oriented tasks were used to assign subjects to different groups. Current HFS was measured before and after application of each self-regulation technique by using a multi-level set of HFS indices that includes measures of checking task performance (productivity and accuracy indicators); the current states self-estimations (indicators of state anxiety, subjective comfort, well-being, activity and mood); and physiological measures (heart rate, systolic and diastolic blood pressure, vegetative index Kerdo). Such three-level estimation is regarded to provide a complete description of HFS syndromes (Leonova, 2003).

In the study there were applied two types of self-regulation techniques to each subject: (1) progressive neuro-muscular relaxation and (2) sensory reproduction. The difference between these two self-regulation procedures consists in the type of exercises included in the relaxation session. These exercises are related to different imagery modalities: progressive relaxation technique relies primarily on kinesthetic images; sensory reproduction provokes extensive use of visual images. 
The results in the student sample were the following. As shown by the results of systematic comparisons by t-test the vividness of the visual images' representation allows subdividing the whole sample into the visual and the kinaesthetic groups. It was significantly higher in the visual group $(\mathrm{N}=131, p<0.001)$. The results were reversed for the kinaesthetic group - these subjects had much more vivid kinaesthetic representations $(\mathrm{N}=131, p<0.001)$. The same type of comparisons was performed for the athletes' samples. Obtained results matched exactly the students' results - the vividness of visual image was significantly higher in the boxers' sample $(\mathrm{N}=16, p<0.01)$ in contrast with the data of judo athletes who have more expressed imaginations in a kinaesthetic sphere $(\mathrm{N}=16$, $p<0.05)$.

Relying on these results, the second stage of data analysis was realized. It concerns differentiating the effects of the used self-regulation techniques on the complex of HFS manifestations in different groups of subjects. Group comparisons of the whole set of HFS indices (processed by paired t-tests) revealed that in the visual group the complete positive effect was induced by the technique of sensory reproduction $(p<0.05)$. On the contrary, for the kinaesthetic group the most expressed positive effect was associated with the technique of progressive relaxation $(p<0.05)$. The deviation from this tendency was found only for physiological measures (indices of blood pressure and heart rate). They were optimized in all cases after both self-regulation sessions. All summarized data are presented in Table 4.

Table 4

Interpretation of obtained self-regulation effects in the students (based on the t-test data, $p<0.01$ )

\begin{tabular}{|c|c|c|c|c|}
\hline \multirow{2}{*}{ State indices } & \multicolumn{2}{|c|}{ Progressive relaxation } & \multicolumn{2}{c|}{ Sensory reproduction } \\
\cline { 2 - 5 } & $\begin{array}{c}\text { Visual group } \\
(\mathrm{N}=73)\end{array}$ & $\begin{array}{c}\text { Kinaesthetic } \\
\text { group } \\
(\mathrm{N}=58)\end{array}$ & $\begin{array}{c}\text { Visual group } \\
(\mathrm{N}=73)\end{array}$ & $\begin{array}{c}\text { Kinaesthetic } \\
\text { group } \\
(\mathrm{N}=58)\end{array}$ \\
\hline $\begin{array}{c}\text { Well-being } \\
\text { scales }\end{array}$ & $\begin{array}{c}\text { Negative } \\
\text { decrease or no } \\
\text { changes }\end{array}$ & $\begin{array}{c}\text { Positive strong } \\
\text { increase }\end{array}$ & Positive increase & $\begin{array}{c}\text { Positive increase } \\
\text { or no changes }\end{array}$ \\
\hline $\begin{array}{c}\text { Physiological } \\
\text { measures }\end{array}$ & Positive increase & $\begin{array}{c}\text { Positive increase } \\
\text { or no changes }\end{array}$ & Positive increase & No changes \\
\hline $\begin{array}{c}\text { Job perfor- } \\
\text { mance }\end{array}$ & No changes & $\begin{array}{c}\text { Positive strong } \\
\text { increase }\end{array}$ & Positive increase & No changes \\
\hline
\end{tabular}


In the athletes' sample the same type of results were obtained (see Table 5). Boxers were more receptive to the sensory reproduction effects because of two important facts. The HFS self-esteems as measured by well-being and state anxiety scales decreased significantly after the progressive relaxation session. Sensory reproduction has an influence on the whole set of HFS indicators: improvement of the mood and state-anxiety level, normalization of blood pressure and heart rate indices and even enhancement one of the cognitive performance indicators (task accuracy). Another situation was observed in the judo group. Progressive relaxation had a more distinct effect on this group: after this session the indices of state anxiety and accuracy of performing cognitive tasks were significantly improved. At the same time, there were no any significant changes after the sensory reproduction session in the judo group.

Table 5

The efficiency of self-regulation techniques in the athletes' groups (based on Wilcoxon signed ranks test, $p<0.05$ )

\begin{tabular}{|c|c|c|c|c|}
\hline \multirow[b]{2}{*}{ State indices } & \multicolumn{2}{|c|}{ Progressive relaxation } & \multicolumn{2}{|c|}{ Sensory reproduction } \\
\hline & $\begin{array}{c}\text { Visual group: } \\
\text { boxing } \\
(\mathrm{N}=7) \\
\end{array}$ & $\begin{array}{l}\text { Kinaesthetic } \\
\text { group: judo } \\
(\mathrm{N}=9)\end{array}$ & $\begin{array}{c}\text { Visual group: } \\
\text { boxing } \\
(\mathrm{N}=7) \\
\end{array}$ & $\begin{array}{c}\text { Kinaesthetic } \\
\text { group: judo } \\
(\mathrm{N}=9)\end{array}$ \\
\hline $\begin{array}{l}\text { Well-being } \\
\text { scales }\end{array}$ & Positive increase & Positive increase & Positive increase & No changes \\
\hline $\begin{array}{l}\text { Physiologi- } \\
\text { cal measures }\end{array}$ & $\begin{array}{l}\text { Shift to normal- } \\
\text { ization }\end{array}$ & No changes & $\begin{array}{l}\text { Shift to normal- } \\
\text { ization }\end{array}$ & No changes \\
\hline $\begin{array}{l}\text { Job perfor- } \\
\text { mance }\end{array}$ & No changes & $\begin{array}{l}\text { Negative de- } \\
\text { crease }\end{array}$ & $\begin{array}{l}\text { Negative de- } \\
\text { crease }\end{array}$ & No changes \\
\hline
\end{tabular}

The main result of the presented study demonstrates that there is a selective sensibility to the influence of different self-regulation techniques which is corresponding to the dominant sensory modality of the participants. These data show that progressive relaxation has a more distinct effect on the subjects of kinaesthetic group, and has no strong effect on the subjects of the visual group. On the other hand, sensory reproduction has a more distinct effect on the subjects with dominant visual modality. These findings support our initial suggestion that individual differences could play an important role in the successful acquisition of self-regulation skills. It is necessary to emphasize a particular 
psychological sense of the distinguished individual characteristic. The dominant sensory modality in image constructing does not correspond with a set of some single personality or temperament traits. It is a more complex individual ability that can be formed under the influence of life experience of a subject, including professional demands of the specific types of work.

\section{Conclusions and recommendations}

The described results of a series of our studies provide an opportunity to formulate basic principles and to elaborate general recommendations for the practical implementation of self-regulation training programs. Systematic self-regulation training leads to a wide range of immediate and cumulated positive effects on a worker's state and improvement of his / her workability. These positive changes are clearly presented in the data of restructuring of negative HFS syndromes, both actual and chronic. Accordingly, it is recommended to conduct self-regulation training courses during work shifts in order to prevent the negative consequences of intensive workloads and to avoid high-pressure job environments. The application of self-regulation techniques is also recommended to implement in the form of short and intensive "active rest pauses" with a parallel control of achieved levels of recovery. Self-regulation methods are the most efficient in respect to those components of HFS that suffer more from intensive physical and mental loads which are typical for an everyday flow of work activities in different job settings.

The level of optimization effect can be differentiated depending on the type of self-regulation techniques. According to professional specificity their application should correspond to the dominant type of complications or deterioration in activity regulation process in particular occupational groups. Besides, the choice of an adequate self-regulation technique could be based on the causal analysis of typical work errors. If errors are caused by physical and mental exhaustion during prolonged work without rest, those self-regulation techniques would be more helpful if they allow to reduce psychophysiological tension and to increase feelings of subjective comfort and affective attitudes to work. Progressive relaxation training can be an example of such techniques. If distortions of job performance are caused by mental difficulties in work (i.e., intense cognitive demands, high responsibility, emotional strains, etc.) 
such psychologically enriched techniques as sensory-motor imagination or autogenic training seem to be more preferable.

Also, on the basis of obtained results some recommendations concerning application of different self-regulation techniques could be given. In the case of a single implementation of self-regulation methods - some kind of presentation without any systematic skill learning - it is important to take into account a dominant sensory modality of the participants in order to select the most appropriate self-regulation technique. It is recommended to use self-regulation methods in strict accordance with the dominant sensory modality of the subjects in order to achieve more distinct positive effects. In the courses of long-term learning the main purpose consists in a development of a variety of self-regulation skills. It put accent on forming those sensory modalities and imagination abilities which are not dominant in order to provide subjects with different coping strategies. This type of self-regulation training makes people more stable in their emotional responses and more stress-resistant to challenges of professional life.

\section{References}

Barabanshchikova, V.V., \& Kuznetsova, A.S. (2003). Razrabotka programm psihoprofilaktiki professional'nogo stressa na baze analiza psihologičeskih rezul'tatov samoregulâcii sostoâniâ [Stress-Management Programs Elaboration on the Base of Self-Regulation Resources]. In A.V. Kalueff (Ed.), Stress i povedenie: materialy 7-j meždisciplinarnoj meždunarodnoj konferencii po biologičeskoj psihiatrii [Stress and Behavior: Proceedings of the $7^{\text {th }}$ Multidisciplinary International Conference on Biological Psychiatry] (pp. 119-121). Moscow: Rossijskoe obŝestvo psihiatrii.

Benson, H. (1999). The relaxation response. New York: Avon books.

De Keyser, V., \& Leonova, A. (Eds.). (2001). Error Prevention and Well Being at Work in Western Europe and Russia: Psychological Traditions and New Trends. Dordrecht: Kluwer Academic Publ.

Dikaya, L.G. (2003). Psihičeskâ̂ samoregulâciâ funkcional'nogo sostoâniâ čeloveka [Psychological Self-Regulation of Human Functional States]. Moscow: IP RAN.

Dikaya, L.G., \& Semikin, V.V. (1991). Reguliruûŝaâ rol' obraza funkcional'nogo sostoâniâ v èksperimental'nyh usloviâh deâtel'nosti [The Regulative Role of the Representation of Operator Functional State under Extreme Work Conditions]. Psihologičeskij žurnal, 12 (1), 55-65.

Everly, G.S., \& Rosenfeld, R. (1981). The Nature and Treatment of Stress Response. New York: Plenum press. 
Grimak, L.P., \& Khachaturiants, L.S. (1981). Problemy upravleniâ sostoâniem čeloveka-operatora [Problems of the Control over Operator States]. In B.F. Lomov \& V.A. Ponomarenko (Eds.), Deâtel'nost' kosmonavta i povyšenie ee èffektivnosti [On Activity of Austronauts During Flight and on Improvement in their Efficiency] (pp. 116-137). Moscow: Mašinostroenie.

Hilgard, E.R. (1977). Divided Consciousness: Multiple Controls in Human Thought and Action. New York: John Wiley \& Sons.

Hockey, G.R.J., Gaillard, A.W.K., \& Burov, O. (Eds). (2003). Operator Functional State: The Assessment and Prediction of Human Performance Degradation in Complex Tasks. Amsterdam, Berlin, Oxford, Tokyo, Washington, DC: IOS Press.

Jacobson, E. (1978). You Must Relax. New York: McGraw-Hill.

Kuznetsova, A.S., \& Barabanshchikova, V.V. (2005). The Effects of Self-Regulation Techniques on Human Functional States: The Moderating Role of Dominant Sensory Modality. Review of Psychology, 12 (1), 45-53.

Lequerica, A., Rapport, L., Axelrod, B.N., Telmet, K., \& Whitman, R.D. (2002). Subjective and Objective Assessment Methods of Mental Imagery Control: Construct Validations of Self-Report Measures. Journal of Clinical and Experimental Neuropsychology (Neuropsychology, Development and Cognition: Section A), 8 (24), 1103-1116.

Leonova, A.B. (1994). Industrial and Organizational Psychology in Russia: The Concept of Human Functional States and Applied Stress Research. In C.L. Cooper \& I.T. Robertson (Eds.), International Review of Industrial and Organizational Psychology (Vol. 9, pp. 183-212). Chichester: John Wiley \& Sons Ltd.

Leonova, A.B. (1996). Occupational Stress, Personnel Adaptation, and Health. In C.D. Spielberger \& I.G. Sarason (Eds.), Stress and Emotion: Anxiety, Anger, and Curiosity (Vol. 16, pp. 109-125). Washington, DC: Taylor \& Francis.

Leonova, A.B. (2003). Functional Status and Regulatory Processes in Stress Management. In G.R.J. Hockey, A.W.K. Gaillard, \& O. Burov (Eds.), Operator Functional State: The Assessment and Prediction of Human Performance Degradation in Complex Tasks (pp. 36-52). Amsterdam, Berlin, Oxford, Tokyo, Washington, DC: IOS Press.

Leonova, A.B. (2007). Strukturno-integrativnyj podhod k analizu funkcional'nyh sostoânij čeloveka [Structural-Integrative Approach to Human Functional States]. Vestnik Moskovskogo universiteta. Seriâ 14 "Psihologiâ," 1, 87-103.

Leonova, A.B., \& Kuznetsova, A.S. (1993). Psikhoprofilaktika stressov [Psychoprophilactics of Stress]. Moscow: MGU.

Leonova, A.B., \& Kuznetsova, A.S. (2007). Psihologičeskie tehnologii upravleniâ sostoâniem čeloveka [Psychological Technologies of Human State Management]. Moscow: Smysl.

Lobzin, V.S., \& Reshetnikov, M.M. (1986). Autogennaâ trenirovka [Autogenic Training]. Moscow: Medicina. 
Luthe, W. (Ed.). (1969-1974). Autogenic Therapy: Vol. 1-6. New York: Grune \& Stratton.

Marks, D.F. (1999). Consciousness, Mental Imagery and Action. British Journal of Psychology, 90, 567-585.

Marishchuk, V.L., Platonov, K.K., \& Pletnitsky, E.A. (1969). Napryajennost v polete [Tension in Flights]. Moscow: Voenizdat.

Mitchell, L. (1977). Simple Relaxation. London: John Murray.

Naenko, N.I. (1976). Psihičeskâ̂ naprâžennost' [Mental Tension]. Moscow: MGU.

Schultz, J.H. (1983). Ubungsheft fur das autogene Training [Handbook of Autogenic Training]. Stuttgart, Germany: Georg Thieme Verlag.

Zincheko, V.P., \& Munipov, V.M. (2001).Ergonomika [Ergonomics]. Moscow:Logos. 